of paracentesis thoracis. The patient, therefore, was subjected to medical treatment, which appeared for a time to be followed by a good result; certain it is, that absorption had commenced, and in some degree had proceeded, as the gradual diminution of the capacity of the left side of the chest, and partial return to its place of the heart, proved. In a word, so far as the empyema was concerned, the case seemed to proceed favourably; but then the patient's health became deteriorated by the advance of tubercular disease in the right lung, and then the affection of the left side underwent a new change. The purulent fluid had itself made its way out of the cavity of the chest, and, elevating the skin, pointed posteriorly. The medical attendant opened the abscess, and through this opening a large quantity of purulent fluid, from the cavity of the pleura, escaped, and from day to day this side of the chest diminished in size, and a fistulous opening remained; but it does not appear that the patient was benefited by the occurrence, as colliquative symptoms soon set in, and these, with the advance of tubercular disease in the right lung, soon proved fatal.-April 1, 1848.

\title{
MEDICAL MISCELLANY.
}

\section{Case of Hypertrophy with Abscess of the Pituitary Body. By T. P. HESLOP, M. D.}

THE following brief account of this very uncommon lesion occurring in a body so little understood as the pituitary body, I think it useful to put upon record.

J. H., twenty-six years of age, an engineer, of active habits, and subject to exposure to bad weather, was attacked with most acute pain in the head on the 11 th of February, 1848, after dancing almost all the night previously. Though up to this period robust, and in constant employment with the duties of his arduous profession, he had been very delicate in early youth, and inherited a very strong phthisical predisposition. Subsequently, it was remarked to me by a friend who had opportunities of seeing my patient daily, that for six or eight weeks before he had exhibited an extraordinary tendency to sleep. If he sat down, he would immediately fall into a heavy sleep, almost amounting to stupor; but the sudden supervention of the acute pain referred to was the first symptom that attracted attention to his condition. After using some domestic remedies for a day or two, such as constantly bathing his forehead with cold diluted vinegar, from which he derived no benefit, he sought medical advice. He was then treated for "bilious headach," with some simple medicines, and in a few days the pain was very much relieved, and the slight concurrent feverish symptoms disappeared. Unfortunately, he now persisted in examining his busi- 
ness papers, and committed some dietetic errors; these imprudences were followed by a return of the pain with renewed force. Now, too, he began to be excited, restless, and to talk wildly ; or, on the other hand, he would lie in a state of semi-stupor, silent, and absolutely indifferent to every thing around him. His pulse became quick, and he lost all appetite; still his attendant thought the case one of no great importance, - a kind of stomach derangement, and so on. In health he had a jocose, way ward, and half-mischievous way about him; and, it must be confessed, his wild talking appeared very easily to be only an exaggeration of his ordinary manner. In the midst of all this,-_four or five mornings after the renewed attack,--he stripped himself perfectly naked, jumped out of bed, and passed a stool on the floor while standing before his attendant and the physician. This was a " glaring instance." The joke-theory scarcely comprehended this. Consultations were held, mercury given vigorously, leeches and blisters applied. Nothing gave a decided check to the progress of disease, and he fell into a state of profound coma. The pulse became intermittent and very slow, some days even below 40 in the minute. It was now believed that he was in fever. Matters certainly came to a crisis on the evening of about the eleventh day after the supervention of distinct symptoms. His pulse became almost imperceptible,-extremities cold, - hands convulsively clenched,-jaws so firmly closed that, but for the cavity left by the loss of a tooth, nothing could have been poured down the throat. Wine was given freely, yet with caution; another blister was applied to the back of the neck, and from this day a gradual improvement took place, doubtless ascribable to the mercury which had commenced to affect the mouth, and the other judicious means which had been employed. My own personal knowledge of the case dates from this period. With careful support and stimulation he rapidly rallied, and, though occasionally retrograding and showing some of his former bad symptoms, twelve days afterwards he was so rational, and had so good an appetite, that I confidently predicted an early and complete recovery. Yet two symptoms remained which caused me some misgivings. One of these was an almost total loss of memory; a few minutes after taking a glass of wine he would utterly forget having had it. No evidence, no chain of facts could induce him to believe he was in Ireland and not in Sussex, where he had spent a few days two or three years before. The other ill-ominous symptom to which I refer was loss of power over the sphincters. Now and then he would give signs that he wished to pass a stool, but the rule was, that it was voided unconsciously and without warning; and when he occasionally did ask for the urinal, it was almost certain that he would pass water before the attendant could give the utensil to him, so sudden and urgent was the impulse to evacuate the contents of the bladder. However, he was deemed sufficiently well a fortnight afterwards to undertake a journey of sixty miles to Dublin; upon arriving in which city he was put under the care of Dr. Stokes. It would be wearisome to go into any thing like a detailed description 
of the many phases of a chronic and ever-varying disease; it may suffice to state, that he soon altogether lost control over the sphincters, that he progressively emaciated, and that his memory appeared to have almost vanished; still, when tolerably well, he retained a considerable amount of intelligence, and frequently answered questions quite coherently, though so unwilling to speak that whole days would pass without his saying more than "yes" or "no" occasionally. The idea irresistibly conveyed to the mind was, that had the single faculty of memory been perfect, the intellect would have been sound. With the exception already given, he had paralysis of only one muscle-the orbicularis of the right eye-lid, which for several months before his death he did not close, sleeping or waking. The acute pains in the head never forsook him. Sometimes several days passed over without these attacks, but they were rarely more than two days apart; these always came on suddenly, when the face instantly became of a scarlet hue. While strong enough he raised his hands to the head and gave a look, and uttered groans, too distinctly pourtraying the agony of the moment. 'The paroxysm rarely lasted more than ten or fifteen minutes, and was always succeeded by a profound stupor of some hours' duration. At various periods he suffered also from severe cramps of the lower extremities. Towards the end of August it became obvious that the strength was nearly exhausted; but he was destined to give another illustration of the law that chronic disease kills by giving the predisposition to an acute one. An obscure attack of pleurisy came on, of which he died on the 4 th of September.

Autopsy, thirty Hours after Death.-The body was extremely emaciated; upon taking off the calvarium the membranes covering the hemispheres of the brain appeared quite healthy; we then proceeded to detach the brain from the base of the skull; when we arrived at the second pair of nerves, we found them almost surrounded by a softish, dark grey tumour, about the size of a large walnut, occupying the position of the pituitary body on the sella turcica, but extending much beyond the space usually held by that body both posteriorly and laterally; it was very carefully dissected from the dura mater and surrounding structures, but not without slightly lacerating it and giving exit to a small quantity of thick, dark red, purulent-looking fluid. Having taken the brain out of the skull, and turned its base upwards, we examined the exact relations of the tumour; in this position it filled the entire interpeduncular space, extending backwards to the pons varolii, forwards and laterally protruding into the conmencement of the fissure of Sylvius; the crura cerebri were distinctly pressed outwards, so that the space just referred to was greater than natural; it could be easily raised from its position after dissecting off a few delicate cellular bands, having no other connexion with the brain than through the pituitary body, which seemed lost in the tumour: or rather this latter seemed a cystiform enlargement of that body containing the purulentlooking fluid I have already described. Underneath the tumour we 
observed a small quantity of thin fluid, of a slightly reddish tinge, upon drawing off which we remarked that it was but the surface of a more deeply situated fluid, contained in the lateral ventricles. Twelve or fourteen drachms were measured, but probably an equal quantity lay on the base of the skull, of which no note was taken; in fact, the tumour occupied not merely the floor, but almost the entire cavity of the third ventricle; the anatomical relations of the former were precisely identical with those of the latter. The quadrigeminal bodies, we thought, seemed flattened in the antero-posterior direction by the pressure of the tumour.

When we add an increased firmness on section of the medulla oblongata, and slight opacity, with thickening of the arachnoid, over the middle lobes of the base of the brain, we have mentioned all the morbid appearances in the encephalon. But we must record the fact that the bones entering into the formation of the middle fossa of the base of the skull had, scattered over various parts of them, curious little stalactitic processes or exostoses, varying from one to three or four lines in length: the elevations, too, corresponding to the sulci of the middle lobes of the brain, were extremely sharp and angúlar. I shall not stop to inquire whether these had any, or what share in the production of the remarkable disease under which this gentleman suffered. No tubercle could be found in the lungs. There was a considerable amount of recent lymph over the base of the left lung and corresponding surface of the diaphragm.

Two Cases of Acute Glanders in Man. By Henry Graves, M. B., F. R. C. S.I., Cookstown Dispensary.

Is the long catalogue of suffering there is no disease more painfully or more hopelessly interesting to the physician than glanders, when it appears in the human subject. Since the year 1821 , when the attention of the profession was first directed to these cases, so many reports have been published in various periodicals, both at home and abroad, fully corroborating the views advanced by Dr. Elliotson and others, as to the communicability of this disease to man, that at the present day no one has a reasonable doubt on the subject. We must, however, regret, that, though much has been written, as yet little advance has been made in the treatment of those miserable sufferers.

The two following cases are recorded in the hope that they may elicit further information. Possibly those who have not heretofore seen the disease may recognise it by their attention being again called to the peculiar appearance of the areola here noticed, confirming in every particular the accurate description given by Dr. Bigger $(a)$, and by Dr. M'Donnell of the Richmond Hospital, in a case quoted by Dr. Graves $(b)$. As I am of opinion that in glan-

(a) Dublin Med. Jour., First Series, vol. xv. p. 476.

(b) Clinical Medicine, second edition, vol. ii. p. 332. 
ders human aid (as far as our present knowledge extends) is powerless, further than in some degree to alleviate suffering by the judicious employment of opiates, medical men are bound to give the earliest intimation to the relatives of the patient of his almost hopeless state. It is only in the commencement of the disease that the mental faculties are unimpaired; and, to lay aside all religious considerations, it may be necessary to arrange a thousand worldly affairs which must occupy more or less time: besides, the careless use of clothes, sponges, basins, \&c., may cause the loss of more than one life. How valuable then is an early diagnosis I

CASE I.-Michael Magurk, aged 45, a strong, healthy man, of remarkable muscular development, was attacked on Tuesday, 11 th April, with rigors, pain in the heal, joints, and back, restlessness, and excessive thirst. I saw him on the 16th, his friends supposing he had fever, and found him in the following condition: expression of countenance heavy and stupid; eyes watery; conjunctiva somewhat suffused; skin hot and dry; tongue covered with a thick creamy fur; bowels confined; pulse 72, soft and regular; he complained of extreme thirst, and dryness of the fauces, pain.in the back, shoulders, neck, and arms, particularly on the left side. I found that he had " a sore hand," which did not seem to give him much annoyance; however, on examination, I was so much struck with the remarkable appearance presented by the ulcer and a small pustule on the hand and back of the wrist of the patient, that I at once, perhaps rather abruptly, asked, "had he been employed about sick horses?" and, being answered in the affirmative, without besitation formed an unfavourable prognosis on the case. It is not easy to convey an accurate idea of the ulcer and pustule that so strikingly arrested my attention. The former was situated on the outer side of the left hand, about the middle of the metacarpal bone of the little finger, in size nearly as large as a half-crown piece, of a blackish purple in the centre, shading down at the edges to red, and beyond this there was a distinctly elevated ridge or wheal of white; the integument had given way, and from it exuded a thin, ichorous discharge; the latter was on the back of the wrist, not larger than a splitpea, with a yellow summit, surrounded by a red base, and, external to all, the hard, elevated, white ring, which may be looked upon as perfectly distinctive in glanders. At the bend of the elbow a small enlarged gland could be felt, and a second was perceptible in the axilla; these were but slightly painful to the touch, and I could not trace any hardened or enlarged lymphatics leading up the arm. On the previous Sunday he assisted in skinning a horse that died of glanders, having at the time a " hack on his hand." I ordered a poultice to the sore; effervescing draughts ad libitum; and two aperient pills at bed time.

On the 18th he was extremely anxious about his illness, and expressed great fears as to the result; he complained of intense thirst, general lassitude; severe pain in the back; with frontal headach, and dryness of the nose; he was very restless during the night, and 
raved a little; pulse 79 ; the tongue was heavily coated, and the bowels still rather confined. His hand had been constantly poulticed, and, he assured me, it was not at all painful, though, on examination, I found that some amount of sloughing had taken place in the centre of the ulcer: his hand and fore-arm were considerably swollen. Four pustules had come out on his chest, exactly similar to the one before described, each surrounded by the peculiar elevated, hardened, and white zone; the glands in the axilla and bend of the arm did not seem to be larger than on the 16th; he complained greatly of pain and heat in both his ankles, calves of his legs, and knees; each joint was somewhat swollen, and the integuments were rather redder than natural. Ordered to take a small quantity of stimulant (punch); an opiate at bed time.

As this man lived a considerable distance from my residence, I was unable to visit him till the 20 th, when $I$ found that a very marked change had taken place: his features were pinched and anxious; he lay bathed in perspiration; and, since the previous day, had suffered from profuse diarrhœe; upwards of twenty offensive, slimy stools had been passed within twenty-four hours; his tongue was covered with a yellow fur, the papillæ at the edges much elevated; pulse 120, weak; thirst unquenchable; pain in back and head (frontal) unabated; restlessness very great; he slept but little during the last two nights, and raved almost incessantly, though when spoken to he answered in a rational manner; the chest, arms, and legs, were covered with a crop of pustules in all stages, some just formed, with a minute vesicle in the centre, apparently filled with serum, in others more advanced, the vesicle containing pus, while in a third set (few in number) the pus had become dry, the scale had fallen off, and a depression was left in its place, seemingly covered with a thin pedicle from which a watery fluid exuded; all, however, were surrounded by the characteristic circumferential wheal, more or less plainly marked, but the more advanced the pustule the less evident was this appearance; his joints were much swollen and exceedingly painful; the calves of his legs, quite black, seemed as if they had been severely bruised. Sloughing of the hand had proceeded to great extent; the metacarpal bones were visible at the bottom of the sore, from which the discharge was highly fetid, dark, grumous, and profuse; a number of soft, ash-coloured, gelatinous granulations were springing up from the bones; these broke down when touched by a probe. He had a slight cough, and complained of "a stuffing in his nose, and a bad smell;" there was slight discharge of thin purulent matter from the left nostril, and a trifling swelling and redness of the corresponding cheek. I ordered an astringent mixture; an opiate at bed-time; an effervescing draught; port wine and water during the day.

21 st. All the symptoms aggravated; no sleep; delirium almost constant; diarrhoea unabated; tongue brown, dry, and tremulous; teeth covered with sordes; thirst most distressing; pulse 110, weak 
and irregular; face red and much swollen; great discharge from both nostrils, and from the left eye, which was quite closed; his legs and arms were swollen and discoloured; effusion had taken place into all the larger joints. In a lucid moment, on being questioned, the unfortunate patient exclaimed: " $\mathrm{Oh}$, give me sleep; I am pains all over ; you could not lay a finger on a part that is not sore." The stench of the apartment was so great that I was glad to hurry away and breathe a pure atmosphere.

22nd. He died about six o'olock in the morning. I was informed that shortly after my visit he fell into a state of coma, and lay perfectly insensible till released from his sufferings, thirteen days after the introduction of the virus into the system, and eleven from the first appearance of the symptoms. No post mortem was permitted by the relatives.

CAsE II.-_Owen Conwell, aged 38, a strong labourer, assisted in skinning the same horse by which Magurk was infected, and, being a country farrier, examined the lungs and intestines of the animal. I could not learn that he had any cut or abration of the hands at the time, but a slight scratch would easily escape notice; and being brought much in contact with the diseased mass it is not difficult to trace the introduction of the virus into the system. On the night of Monday, 10th, he was attacked with rigors, pain in the back and head, and great thirst; he slept little, and was very restless. On the 16th I visited him; he was then complaining of great pain in the right arm and shoulder, which was much swollen and red, the redness disappearing under the pressure of the finger, and conveying to the touch a "boggy" feel. There were several pustules, exactly similar to those described in Magurk's case, on his chest and arms, and one on the right cheek; these, he said, he first noticed on the previous day. He suffered great pain in his shoulder and back, and indeed in nearly all his joints; his thirst was insatiable; tongue dry and furred; pulse 96 ; some tendency to diarrhoa, but this was supposed to arise from one or two doses of salts which he had taken at the commencement of his illness: he was extremely anxious about his condition, alarmed by the reports that had reached him of my other patient.

I was able to visit this man only once again, namely, on the morning of the 20th, he was then evidently in articulo mortis, running profusely from the nose and right eye, covered with pustules; and, from all I could learn, the two cases seemed to progress pari pasu; the diarrhœa was persistent; coma came on during the night of the $18 \mathrm{th}$, and he expired a few hours after I saw him. No post mortem was allowed.

The similarity of these two cases in their symptoms, progress, and event, must strike the most superficial observer. Both were infected by the same animal, at the same time, and under circumstances of the same kind; in both the virus lay dormant for only a few hours; they were attacked by the first symptoms of their dis- 
euse within a short period of each other; the eruption appeared in both on the fifth day from inoculation; and even in the date of their death there was little difference.

I will not trouble the readers of this Journal with any remarks on the "differential diagnosis" of a disease which has not unfrequently been mistaken for acute rheumatism, fever, \&c. \&c.; but, in concluding, I may be permitted once more to point to the "circumferential elevated white zone," external to the redness, surrounding the pustule; when this appears, I think the practitioner need have little hesitation in declaring that his patient is suffering from one of the most fatal maladies with which we are acquainted.

\section{Cases of Injury of the Head. By J. Pureroy, M. D., Cloughjordan.}

Severe Case of Concussion of the Brain.-J. R., aged 26, was severely beaten with a spade-handle about seven hours before I visited him, on the 17th of August, 1847. Complete insensibility, with loss of speech and vomiting, followed immediately upon the injury being inflicted.

At visit he was found pale and cold; pupils contracted but moveable: pulse 60, small, compressible, and regular.; respiration slow and oppressed, but not stertorous. A cut was found extending across the vertex, about an inch and a half in length, and a soft, diffused tumour, of the size of a crown piece, immediately above the left ear: but no fracture could be discovered. On the 20th inst. convulsive movements of the muscles of the face were observed, recurring two or three times in the course of an hour. Whilst these convulsive movements continued the pupils slowly dilated to a considerable degree, and as they subsided the pupils gradually returned to their previons contracted state, leaving the patient in profound stupor. From the occurrence of the convulsions the stupor had much increased; the patient passed into complete coma,discharged the stools and urine involuntarily, although, up to this period, he was able to stagger out of bed when he felt a desire to empty the bowels or bladder, being unable, however, to call any person to his assistance. On the $23 \mathrm{rd}$ inst. the tumour of the scalp was opened by a triangular incision, and a few clots removed from beneath the detached scalp; but neither fracture nor depression could be discovered, nor any appearance whatever of disease of the bone or of its covering. The convulsive attacks continued, with complete coma; pulse 60 , full, and of good strength, whilst in the recumbent posture, but increased to 84 when the patient was raised up to the sitting posture. The treatment consisted in free and repeated bleeding from the arm, leeches and cold applications to the head, together with purgatives and alterative doses of calomel, with tartar emetic. On the 29 th inst., just twelve days after the receipt of this dreadful injury, the patient made an effort to answer questions when loudly spoken to; his pulse had gradually got up to 84 in the minute, although the pupils continued widely dilated for some days longer. 
From this date convalescence, although very slow, was progressive; the patient made an excellent recovery, and I am not aware that he continued to feel any injurious effect whatever in consequence of the injury.

Fracture with Depression; injurious Effects following at a remote Period after the Occurrence of the Injury.-P. C., a healthy labour $\in$, aged 35, was accidentally struck upon the head, with much force, by a hurl, wielded by an athletic young man, whilst hurling, early in the month of March, 1847. He was knocked down and rendered quite insensible by the blow, and suffered from vomiting for two or three days after the accident had occurred, accompanied by coma, slow, labouring pulse, and paralysis of the right arm, the blow having been struck just above the left ear. The most active antiphlogistic treatment was employed for ten or fourteen days, together with the use of mercury to affect the gums; and at the end of a month the patient was apparently restored to perfect health. The only unpleasant symptoms remaining were, a slight sense of numbness in the right fingers, extending along the arm, together with an unusual irritability of temper. He followed his usual avocations and enjoyed excellent health until the following October, when one morning, unfortunately, he was thrown into a state of the most violent mental excitement, after having endured much bodily fatigue. The immediate effects were that he fell down in a fit of epileptic convulsions, when he was promptly bled and purged, with temporary relief, but from this' date he became an irritable and unhappy epileptic. 'The premonitory symptoms were remarkable ; the eyes became bright, animated, fixed, and slightly suffused; a distinct tingling sensation, proceeding from the fingers upwards, along the right arm, and into the right cheek, which becomes slightly convulsed, the angle of the mouth being drawn towards the right ear, then follows immediately the epileptic fit. On examining the head there appeared a depressed fracture of the skull, of an oval form, fully an inch and a half in length, and an inch and a quarter in breadth. The existence of this depressed fracture was ascertained during his first illness, but as the integuments were whole and sound, and that, at the same time, the bad symptoms yielded to the treatment employed, it was considered inexpedient, in consultation, to attempt to raise the depressed bone by means of an operation.

In the first case, that of concussion of the brain recorded above we have a remarkable combination of symptoms indicating primarily concussion, and at a later period, compression of the brain. The early symptoms, -insensibility, coldness of the extremities, oppressed and feeble pulse, with vomiting,-indicated the occurrence of concussion; whilst, subsequently, convulsions coming on, with a dilated and immoveable condition of the pupils, and profound coma, would seem to point out pretty clearly that there existed a depressed fracture of the skull, or that extravasation of blood had taken place,in either case causing undue pressure of the brain at some point. 
Reasoning thus, it was deemed right to cut down upon the injury, in order to ascertain the existence of depressed fracture; but as there did not exist any depression of the bone, it was determined not to proceed further with the operation. The cause of the convulsions and coma, in this case, can merely be conjectured; perhaps a slight extravasation of blood had taken place into the substance of the brain, and subsequently became absorbed under the influence of mercury, and the active treatment pursued.

The next case of injury of the head affords an instructive example of the very remote period from the receipt of the injury at which severe and distressing symptoms may follow; further, it proves the propriety of raising depressed fracture of the skull occurring in the adult subject, when the operation is practicable, in order to avoid the unhappy consequences which followed in the present instance. As the scalp was not wounded, and that the symptoms yielded to milder measures, it was considered prudent to avoid the risk of a severe operation; yet the result proved that the raising of the depressed fracture might have altogether averted the bad effects which followed upon this injury. Considered in a physiological and moral point of view, the case is interesting, as exhibiting the influence of mental emotions upon the heart and general circulation; and, again, the injurious effects of an over excited circulation upon a brain already predisposed to diseased action.

\section{Letler on the Contagiousness of Cholera. By R. J. Graves, M. D. Merrion-square, October 16, 1848.}

Dear Sir,-In consequence of the appearance of cholera in England since my communication in the present $N$ umber of your Journal was printed, I beg leave to make the following additional observations on the progress of that dicease:

As soon as cholera was established in Hamburgh, it appeared evident to us who advocate its contagious nature, that it was likely to be brought in trading vessels to the ports in England which have the most intercourse with that city; and what has been the fact? In those very ports, viz., Sunderland, Hull, and London, the arrival of cholera has been officially announced!-while not a single case has occurred in any of the numerous villages and small fishing towns on the coast of England between Sunderland and Hull, or between Hull and London. And why have all these towns and villages, which, on the hypothesis of the diffusion of cholera by the spread of some peculiar atmospheric influence, must have suffered quite as early from this influence as any of the three cities actually affected, -why, I ask, have they escaped? The answer is obvious,-because they have no direct communication with Hamburgh.

A melancholy instance of the evil and fatal effects which inevitably follow from an obstinate adherence to the doctrine of the noncontagiousness of cholera, is at this very time exhibited in a convict ship moored in the Thames. A prisoner is attacked with cholera; what means are taken to prevent its affecting his associates? Why

VOL. VI. NO. I 2, N. S. 
they are furnished each with a certain daily allowance of tobacco, and it is soon after announced in all the papers that the smoking has proved quite a luxury to them, has had the best effects on their spirits, and has effectually neutralized the fluviatile malaria. The triumph has been but short-lived, and King James himself could not have sent forth a more effectual counterblast against tobacco than that which issues from the spirit of the following paragraph :

\section{"Woolwicl, October 13, 1848.}

"The cases on board the convict ship Justitia, up to this day, are twenty-five, six new cases having been reported during the previous twenty-four hours; of that number five have died, and one has been discharged; the other eighteen are not apparently in any immediate danger, but are so debilitated that their medical attendants have not considered themselves justified in entering them on the list of recoveries."-Standard, October 14th.

Of course the Government Commissioners will consider this spreading of the disease in a crowded hulk as a decisive proof of its non-contagiousness!! as they have already done with regard to a ship which arrived at Hull. From their report on the latter case, it appears that sailor after sailor died of Asiatic cholera during the voyage from Hamburgh, because, forsooth, they indulged in eating plums and drinking cider. Such indulgences were not likely among the convicts on board the hulk, who used nothing unwholesome until they were set smoking by authority !

It is some satisfaction to find that OxENSTIERN's parvula sapientia presides over the sanitary affairs of Great Britain; for as soon as it was ascertained that the cholera had safely arrived in London, vi $\hat{a}$ Hamburgh, the authorities immediately interfered, and quarantine was established between the two cities I

In conclusion I beg leave to repeat, that the unanimity of all Government officials called on to report on the non-contagiousness of cholera, is a striking proof that nothing is impossible to English Capital.

$$
\text { I remain, dear Sir, faithfully your's, }
$$
Robert J. Graves.

To the Editor of the Dublin Quarterly Journal.

Cases of acute dry Gangrene of the Fingers.

By Maurice Henry Colles, L. R. C. S. I.

IT is the duty of every medical man to put on record curious or anomalous facts. This must serve as my apology for intruding on the profession the notes of three remarkable cases which fell under my notice in the hospital of St. Louis, at Paris, under the care of M. Jobert. They occurred at a period when north-east winds had prevailed for some days; and at such times, in consequence of the close proximity to Montfaucon (the common cess-pool of Paris), hos- 
pital gangrene and erysipelas are very prevalent; and, in fact, during the fortnight, there were several cases of both in St. Louis, and afterwards at the Hotel Dieu; and about the same time a good deal of puerperal fever at the Maternitê. The simultaneous appearance of all these unhealthy forms of inflammation-_ "Talis Hyperboreis aquilo cum densus ab oris incubuit" - has often been there remarked on; and when the wind does not continue long from that quarter, by closing the windows on that side of St. Louis, they generally escape the infection. Whether the miasmatic poison had anything to do with the production of the unusual form of inflammation which I am about to describe, every one must decide for himself : it certainly was the general opinion of those on the spot that it had, though the exact modus operandi none could better explain than by the vague term of constitutional effect; and yet constitutional disturbance occurred only in one of the individuals, and, in his case, evidently from a metallic poison.

Case I.- A man aged about 30, healthy, and strongly made, a servant to an artist, his occupation being to clean his master's studio, palette, brushes, easel, \&c., one morning pricked the ball of his right thumb with a nail, but not more than skin deep. Shortly after he was sent to clean a very dirty palette, and had to use his thumb a good deal to rub off the paints, some of which, of course, contained lead, others arsenie, mercury, \&c. Towards evening he began to feel feverish and hot, his fauces dry and stiff, with a sensation of tingling heat, amounting at last to pain, in the epigastrium; irregular rigors and extreme thirst, but no pain in the thumb. Next day a small white pustule, or opaque vesicle, made its appearance on the scratch or puncture; the thumb became hot, painful, and throbbing; round the vesicle was an areola of an intense livid red. On the third day the apex of the little vesicle was hard and dry, and of a brownish colour, and the inflamed base was more extended. The gangrene continued to creep on for ten days, until the first and half the second phalanx were converted into a dry, hard, brown, shrivelled, horny substance, like burned skin, separated from the living parts by the same circle of livid red; the gangrened parts were destitute of sensation, while all beyond the line was intensely painful. The constitutional symptoms continued only until the third day, or until the local mischief was fully developed. The caustic potash and lime paste (pâte de Vienne) was applied all round the areola, and the disease ceasing to spread, amputation was resorted to at the second joint. The gangrenous inflammation did not return, but nearly two months elapsed before complete cicatrization took place: this was owing, in part, to diminished vitality; in part to unavoidable scantiness of the flap.

CAsE II.-An hospital porter, sallow and thin, aged 45, while bundling up foul linen of the hospital, pricked one of his forefingers with a pin; it felt a little sore at the time, but scarcely more than an ordinary scratch would have done. This case progressed locally exactly as the preceding; there were no constitutional symptoms 
worth mentioning at any period, and the treatment only differed in that the parts were amputated in the middle of the second phalanx while gangrene was still spreading; no previous application of caustic being made. The stump was six weeks in healing, granulations springing up constantly from the cicatrix. There was abundance of covering in this case.

CAsE III.-An hospital nurse, about fifty years of age, thin and sallow, but healthy. The cause, progress, and treatment of this case were exactly the same as in No. 2, except that the part was amputated at the junction of the distal and second phalanges, and in ten days after the injury instead of a fortnight. The seat of gangrene was the right thumb. This was longer healing than either of the others, the flaps being scanty, the vitality impaired, and the subsequent granulations very troublesome, though small.

In comparing these cases in order to get at the causes, some circumstances are to be noted : their occurrence during an epidemic which altered for the worse all local inflammations; the difference they exhibited from the ordinary forms both of this hospital gangrene and of poisoned wounds in general; the difficulty experienced in healing the stumps; and the absence of all fever in two, and the presence of severe constitutional disturbance in the other, ceasing on the appearance of the local gangrene.

\section{Letter on the Subject of intermittent Fever. From Charles Halpin, M. D., Cavan, to Dr. Graves.}

Cavan, September 26, 1848.

My DEAR Srr,-Knowing that the subject of intermittent fever has engaged a good deal of your attention, and feeling that the communication of any facts bearing on this disease will be acceptable to you, I forward you a very brief history of several cases of ague that came under my notice within the last six months.

I should premise that, so far as my experience of this county extends, ague is a very rare disease indeed. During the last eighteen years in which I have had the charge of a dispensary, I have not met with more than one or two cases of it in which the patient had not contracted it in some locality where it was endemic.

The cases I now submit to you are merely intended to show for how long a period the disease may lie dormant in the constitution, after the individual has been exposed to its exciting cause.

In the latter end of $\mathrm{July}, 1847$, the fourteen men whose cases are included in this report, went from the neighbourhood of Shadone, county Cavan, to Lincolnshire, to reap the harvest ; thirteen of them remained until the latter end of September, a period of about six weeks, exposed to the malaria of the fens. The weather was exceedingly hot, and no rain fell in that part of the country for some months. During their sojourn there they drank immense quantities of water. which they all describe as of a most unwholesome character. Notwithstanding, they all returned home in good health, and continued 
so up to the first week in April, 1848. The latter end of the month of March was intensely cold, and a biting easterly wind, veering occasionally to the north-east, set in, and prevailed until the first week in May. The accompanying table exhibits its effects on the harvest-men. Seven of the party were seized, most suddenly, with ague in the first week in April; the eighth man had his first rigor on the 28th of May; and the fourteenth on the list, who remained but a fortnight exposed to the malaria, continued exempt until the 13th of August, when a violent quotidian seized him. It will be seen that just twelve months elapsed between his eutrance into the fens and his consequent illness.

\begin{tabular}{|c|c|c|c|c|c|c|}
\hline No. & Age. & $\begin{array}{c}\text { Arrived at } \\
\text { Lincolnshire. }\end{array}$ & Left the Fens. & $\begin{array}{l}\text { Date of Attack } \\
\text { of Intermittent. }\end{array}$ & $\begin{array}{l}\text { Type of } \\
\text { Fever. }\end{array}$ & $\begin{array}{l}\text { Season in } \\
\text { the Fens. }\end{array}$ \\
\hline 1 & 46 & Aug. 3, 1847. & Sep. 20, 1847. & April 1, 1848. & Quotidian. & Second. \\
\hline 2 & 20 & $"$ & $n$ & & Tertian. & First. \\
\hline 3 & 25 & $"$ & $"$ & April 3, 1848 & $n$ & Second. \\
\hline 4 & 27 & $"$ & $"$ & April 2, 1848 & " & First. \\
\hline 5 & 30 & ", & $"$ & April 1, 1848 & $"$ & " \\
\hline 6 & 25 & $"$ & $"$ & April 4, 1848 & & \\
\hline 7 & 45 & " & $"$ & April 1, 1848. & Quotidian. & Fourth. \\
\hline 8 & 34 & $"$ & $"$ & May 28. & Tertian. & First. \\
\hline 9 & 41 & $"$ & $"$ & $\left\{\begin{array}{r}\text { October 15, } \\
1847(a)\end{array}\right.$ & . $\quad .$. & \\
\hline 10 & 40 & $n$ & $"$ & May, 1848 & Tertian. & \\
\hline 11 & 24 & $"$ & $"$ & . $\quad$. & .. $\quad$. & First. \\
\hline 12 & 26 & "я & $"$ & . $\quad \cdots$ & . $\quad \ldots$ & $"$ \\
\hline 13 & 40 & " & 1 & $\cdots$ & $\therefore \quad$. & Third. \\
\hline 14 & 23 & $"$ & Aug. 17, & Aug. 13, 1848. & Quotidian. & First(b). \\
\hline
\end{tabular}

Of the fourteen men but three have remained exempt from the disease at this date, namely, Nos. 11, 12, and 13. No. 9 had fever a fortnight after his return home, for which he was treated in the county of Cavan fever hospital; during its course he suffered severely from rigors; and No. 10, who went to Liverpool shortly after his return from Lincolnshire, wrote to his friends in Lisnaglea, in the month of May, to say that he had been very ill of ague, that he was then recovering, but still unable to resume his work at the docks.

I shall abstain from entering into the treatment adopted, further than to say that quinine formed the basis of it, and that I have found it to act most satisfactorily when combined with purgatives, as compound powder of jalap, or compound rhubarb pill, in such quantities as insured two or three discharges from the bowels daily. I first saw quinine exhibited in this way by my friend, Dr. Tabuteau, of Portarlington, at Oldcastle, County Meath, in the year 1823 or

(a) This patient had fever, attended with severe rigors, for which he was treated in a fever hospital.

(b) Four of the above had been in the fens previously, yet they never suffered any consequent illness before this time. 
1824, when great numbers of the male population of that district suffered from intermittent fever, whilst, strange to say, the females escaped it altogether.

$$
\begin{gathered}
\text { "I remain yours very faithfully, } \\
\text { " "CHARLEs Halpiv, } \\
\text { "Physician to the County of Cavan } \\
\text { F'ever Hospital. }
\end{gathered}
$$

"To Robert J. Graves, Esq., M. D."

\section{Case of Double Uterus, with Observations upon the Subject of Genera- tion. By John Purcell, M. D., M. R. I. A.}

[Read at a Meeting of the Dublin Medico-Philosophical Society, July 1, $1773(a)$.

Sunce the last time I had the pleasure of meeting this Society, the body of a woman was brought to the anatomical theatre, who was supposed to have died in the last month of her pregnancy. Upon opening the abdomen, the uterus appeared of such a size and form as is generally observed at that period. It contained a full-grown fotus, but was furnished with only one ovarium and one Fallopian tube, which were situated on the right side. On the left was placed a second uterus, unimpregnated, and of the usual size, to which the other ovarium and tube were annexed. But these two uteri were totally distinct and separated from each other, except at the lower extremity of their necks, where their union extended a quarter of an inch, and an acute angle was formed between them. There was nothing extraordinary in the external parts of generation, but from each side of the meatus urinarius a membrane ran downwards, and the two, having comprehended this orifice between them, were joined together a little below it, so as to form by their union a septum or mediastinum, which, taking the remainder of its origin from all that prominent ridge called the superior column, and descending perpendicularly, was inserted into the inferior column, so as to extend from the entrance of the vagina as far backward as its posterior extremity, and thus to divide it into two tubes of nearly equal dimensions. But each of them did not lead solely to the womb of its own side, for the right vagina became gradually wider as it ran backwards, and at last was so far dilated as to comprehend within its circumference the orifice of both uteri, while that on the left side, having taken an oblique direction, ended in a cul de sac or cæcum. Such a conformation might have rendered it totally useless; to pre-

(a) The accompanying most interesting case of Dr. Purcell's is extracted from the Memoirs of the Medico-Philosophical Society of Dublin, vol. iii. p. 59, of which we have already given some account, in the preface to the first Number of the present Series of this Journal. At a future period it is our intention to furnish our readers with a Memoir of this distinguished physician, who, with Drs. Plunket, Quin, and Harvey, enjoyed the most extensive practice in this city towards the close of the last century. When this paper was written, Dr. l'urecll was assistant to Dr. Cleghorn, the professor of anatomy to the University.-Ev. 
vent which, Nature, fertile in expedients, contrived a fissure in the septum, an inch in length, and about an inch distant from the womb of that side. Thus it appears that both uteri might be impregnated through either vagina, as that on the right side led directly to both, and as, by means of the fissure in the septum, the semen could be easily thrown from the left vagina into the right, where the apertures of the two wombs were placed. Through the latter passage both uteri would seem to have an equal chance for impregnation, for, notwithstanding that which contained the fotus was placed almost directly in a line with the axis of the right vagina, yet this, probably, was not its original position, but in process of time its bulk increased so much as necessarily to occupy the middle space, and push the unimpregnated one aside. But, however surprising it may seem at first view, yet there is reason to imagine that the right womb, though at a greater distance, would be much more apt to conceive than the other, and the left vagina only had been made use of; for when this was distended it appeared that the posterior part of the septum, by its protuberance, closed up and covered the left os tincr, and as this would probably be the case in copulation, the semen, not finding a ready adinission into it, would pass over to the right orifice, where its entrance could not be so much obstructed. So that, if we may hazard a conjecture, I think it more likely, since the right uterus only conceived, that the left vagina had been generally employed. And here I must beg leave to remark that this is a most extraordinary, and, I may venture to say, an unparalleled $(a)$ instance, where a short penis would prove more effectual than a long one; for the left vagina ending in a cul de sac, and the fissure in the septum being at a considerable distance from its extremity, a long penis would overshoot the mark and lodge the semen in that part of it which was impervious, whilst one of moderate size, reaching only as far as the fissure, would give the seed a much better chance of being admitted. It was a prevailing opinion amongst the ancients that male children were conceived in the right side of the womb, and female in the left. Having so few opportunities of dissecting human subjects, they depended too much on the analogy of the structure of brutes, which has been the principal source of the many erroneous descriptions we meet with in their works. . It is well known that the uterus of most quadrupeds is divided in to two cornua, in which the fotuses are lodged, and it was not very absurd to conclude that nature might have formed them for the distinct repositories of the two sexes. Accordingly this was supposed to take place also in the human uterus, which has been described and delineated as if distinguished in to two chambers. Hence arose the opinion, which is received in some places to this day, that a very sure prognostic with regard to the sex of the child may be drawn from

(a) In a side note on this page we here find the following observations : "How happens it then that a woman has conceived whose hymen remained entire?-Vide Maur. Ob. 489 and $583 . "$ 
the side of the belly on which the tumour is more sensibly felt. Dissections, being now more frequent, have proved that the human womb consists of one undivided cavity, so that the fœtus, let it come from which tube it may, will, when arrived to a certain size, occupy it entirely. 'This observation, however, is not sufficient to refute the supposition that each sex might have its distinct ovarium; and Morah, a modern author, quoted by Haller, pretends to determine how many males and females any animal has brought forth, by examining the cicatrices or marks on its ovaria. For, in a creature which never had produced any other but females, he found the right ovaria still full of ova, but the left quite exhausted. 'That this is not always the case in brutes appears from the observation of $\mathrm{Dr}$. Harvey, who found male fotuses in the left cornu, and females in the right. In the human subject opportunities of determining this matter must occur very seldom, nor do I know of any instance recorded, except one by Cyprian, where both a boy and a girl were conceived, although the right tube was wanting. But the present case affords a second example, for here the impregnated uterus had not the smallest communication with the left ovarium or tube, and yet it contained a female fotus. The septum was not merely membraneous but fleshy, and of a considerable thickness, and, like most other mediastina in the human body, consisted of two laminæ combined; of these each vagina furnished one, for each had a constrictor of its own, and, being completely surrounded by muscular fibres, had a power of contraction independent of the other, which must be very useful, and could not be effected so well if both vaginæ were comprehended within the same muscular rings, and separated by a membrane incapable of action.

It has been the opinion of many modern authors of the first reputation, that the fundus is that part of the womb whose extent increases in the greatest proportion during pregnancy, and upon this supposition they have founded various theories. One of the principal arguments which they propose in support of their opinion is, that the insertion of the Fallopian tube is removed from the angles of the uterus, and gradually descends towards its neck, so that a short time before delivery they are at a very great distance from their former position. Haller does not pretend to deny these facts, but mentions three instances where the tubes did not change their place. But Petit, in his memoir on the cause and mechanism of childbirth, is clearly of opinion that the whole doctrine is destitute of foundation. He asserts that the fundus increases less than any other part, and that the surprising growth of the womb is effected by a fresh supply of fibres successively furnished by the neck and parts adjoining. As a decisive proof he insists that the insertion of the tubes continues nearly in the same place, and accounts for the error of the above-mentioned authors by observing, that as the fundus is pushed upward by the growth of the other parts, a greater portion of the tube will adhere to the surface of the tube, and then the apparent place of insertion be very far distant from the real one. This remark is verified in the pre- 
sent instance, for the tube at first sight appears to penetrate into the middle of the uterus, but upon a closer inspection, and by introducing a bristle, it is found to run for a considerable space between it and the coat which it receives from the peritonæum, and at length to enter into its cavity not very far from the spot it may be supposed to have occupied before impregnation.

With regard to superfotation, it is evident how easily it might have been in the present subject: and the supposition of a double uterus can easily account for it on many other occasions; but this is matter on which it would be needless to dwell longer, as it has been very fully treated in Gravel's dissertation, published in Haller's collection, where we meet with a similar instance of two uteri and a vagina, the anterior part of which was divided by a septum, but whose posterior portion was single where the septum was discontinued. Haller, in his Opuscula Pathologica, gives the history of a young lady of quality, who had two wombs, each of an oval shape, and furnished with its own peculiar vagina. One of these vagina was anterior, and communicated with the right womb, the other was posterior, and led to the left; and it is worth observing, that in these two cases, and in most others of the same kind which have been hitherto observed, each uterus had only one ovarium and one tube. A double uterus is described by $D^{\prime}$ Acrel, in a treatise printed at Stockholm, in 1762; and in the seventh volume of Haller's Elementa Physiologiæ various authors are referred to who deserve to be consulted on this subject. In some of these we find examples of two wombs, or one womb divided into two cornua, viz. : Mad. la Marche's Instructions to Midwives ; Boehmer's Fasciculus Secundus; the History of the Academy of Science for the years 1705, 1747, and 1752; T. Bauchine; Sylvius; and Julius Obsequens, as quoted by Riólan, though the observation is supposed by many to refer only to the external parts of generation; the Commercium Litterarium Noricum, anni 1733; Levret and Valisnerius, which last describes a case where one of the wombs opened into the rectum. Sometimes the uterus retains its proper external appearance, although it be really double, its cavity being divided by a septum. Of this instances occur in the History of the Academy of Science for the years 1705, 1708, and 1752; in the Ephem. Nat. Curios. Dec. 2, ann. 5 ; in the Acta Mogun ina, T. ii.; in Levert, p.32; in Heuerman; and in Eisenman, of which last a plate is given by Gravel, in his Treatise on Superfotation.

Since, therefore, it appears that in the structure of the parts of generation nature frequently deviates from the ordinary course, practitioners in midwifery ought to consider how many difficulties they may perhaps be exposed to by not attending to the possibility of sometimes meeting with a womb formed like that $I$ have attempted to describe. An attention of this kind would probably have been of the utmost consequence in the present case, for the orifice of the unimpregnated uterus was so far dilated as easily to admit two or three fingers, which must have arisen from the efforts of the midwife to bring on delivery; and the septum was likewise lacerated in two. places, I presume by the like unavailing attempts. 
Thus, Gentlemen, I have endeavoured to give a faint illustration of the annexed drawings, whose merit sufficiently declares them to be the performance of our worthy and ingenious member, Doctor Macbride, to whom I with pleasure acknowledge myself indebted upon this and many other occasions $(a)$. On the Use of Ergot of Rye in Mydriasis. By J. F. M·Evers, M. D.,
Cork.

Cork, October 17, 1848.

IN the London Medical Gazette of September 8, a correspondent notices the peculiar action of ergot of rye upon the iris, discovered by Mons. Comperat; he says that in excessive dilatation from the use of belladonna, powdered ergot of rye, taken like snuff, has the property of contracting the pupil. I tried its effects on several persons, whose irides were strongly under the influence of belladonna, and in no case did the ergot cause any change when employed on the same day with the belladonna, but in every case, on the subsequent morning, whilst the pupils were still largely dilated, the ergot had a marked effect in the course of a few minutes. Thinking, with M. Comperat, that our knowledge of this property of the ergot may be taken advantage of when the pupil is preternaturally dilated from other causes, I was happily enabled to test its efficacy in the following case of mydriasis.

Barnaby Kelly, aged 50, a pensioner, of tall and slender make, had spent the greater part of his life in tropical climates, but returned home with a good constitution. On getting out of bed three weeks ago, he observed excessive lachrymation of the right eye, which has continued since, together with impaired vision. The eye is free from vascularity or pain of any kind, looks healthy in all its parts, except the iris, which presents the appearance of a narrow ring, so largely is the pupil dilated; the iris is perfectly immoveable.

A few pinches of ergot contracted the pupil considerably in a few minutes, whilst a few additional pinches, taken on the following morning, reduced the pupil to its normal standard, the iris assuming the lively motions of healthy action; thus, in a day, completing, as far as the pupil is concerned, the cure of a disease which Demours, and other writers on ophthalmic surgery, tell us cannot be accomplished by a six months' treatment.

This action of ergot of rye on the iris is worth the careful consideration of physiologists, and, I have no doubt, will lead to important results.

(a) The drawings are not to be found among the Memoirs from which this case is quoted. 


\section{MEMOIR OF THE LATE WILLIAM GRIFFIN, M.D., OF LIMERICK $(a)$.}

THE icy hand of death has of late been pressing so heavily on the members of our profession,-its approaches have been so rapid and follow in such quick succession, - so many firesides have been chilled and deserted by its awful visitations, - and such an amount of misery has followed in its train, - as to sicken the heart and render it truly sorrowful. When we recount the noble spirits and the master minds which departed from amongst us, sinking beneath a pestilential scourge, and call to memury a cherished friend, or some fond companion of our early days, our spirits droop within us, and we become filled with gloomy forebodings. The serious injury which the profession has sustained in the loss of so many useful and valuable members, and the dismal tales of woe, which of late days have accumulated upon our attention, had in a measure blunted our acuter feelings, disposing us to give way to a species of fatalism, and to almost persuade ourselves, were we not able to account for it by other causes, that as a body we are doomed to destruction.

But when the announcement of Dr. William Griffin's death fell upon our ears, however apathetic or resigned we might have been disposed to feel,-whatever amount of philosophy we might have summoned to our aid,-we could not avoid being acutely sensible to so heavy a shock.

The name of Griffin carries so many bright associations with it, awakens in the mind so much purity of thought and lofty sentiment, as to claim and call forth our warmest acknowledgment. Who that is familiar with the national works of Gerald Griffin, that has not been carried away in profound admiration of his exquisite genius. The author of the Collegians may be imitated but never can be outrivalled in originality of thought, beauty of conception, powers of description, and faithful imagery. His chaste and eloquent delineations of life and character, so true to nature, and so replete with moral impulse, charming while they instruct, and instructing while they charm,-Deservedly gained for him the unqualified approval of the literary world, and raised up a monument to his fame and his memory both lasting and imperishable.

To the family of Griffin has been conceded the reputation of being highly talented, and that talent, as nature would have ordained it, appeared traceable to the mother's side. William, the subject of this memoir, was the second of five brothers. He was born in the city of Limerick, on the 25th of October, 1794; his father held the position of a respectable country gentleman, one of that class who constitute the worth and respectability of the country

(a) We are indebted to a medical friend in Dublin, the early companion and fellow-student of the late Dr. Griffin, for this memoir. 
in the absence of the lord of the soil, who, unfortunately, in too many instances, is never heard of, save through his agent, when the rentday arrives, or the term of the lease is on the eve of expiring. Some of his forefathers, however, had held in fee large territorial possessions, of which they had been deprived by the operation of laws, the policy, or injustice of which it is not our province to touch upon. His mother was sister to the late Dr. Geary of Limerick, a man of considerable eminence in his profession, and more particularly distinguished for his skill and great success in the treatment of fever.

$\mathrm{He}$ acquired a good classical education, first at the school of $\mathrm{Mr}$. T. O'Brien, and afterwards at that of Mr. Richard M'Eligott, a man of much learning, and a teacher of distinction. While at school he was remarkable for capacity and quickness of comprehension. He was also very industrious, and made rapid progress in his studies. Before his education was well completed he was sent to sea as a midshipman, a mode of life at that period somewhat palatable to his taste. His prepossessing appearance, gaiety, and gentlemanly, unassuming manner, rendered him a favourite with all. 'Through the influence of Sir Vere Hunt, Bart., in the beginning of July, 1809, he entered as a midshipman on board the Venerable, seventy-four, the Flag Ship of the expedition to Flushing in that year, and then under the command of Sir Home Popham and Captain King. She carried out Lord Chatham and his staff, and was soon brought into action in an attack on the batteries, which William describes in a letter home, as a "very new and startling affair," but which was successful in its object without much bloodshed. The Venerable having returned to England was soon despatched for Walcheren again, and on her passage there was wrecked at midnight on the Drogan Sand, off Flushing; her masts had to be cut away, and her cannon and stores were thrown overboard. She was barely kept afloat by constant pumping until morning, when she was towed into dock by her cutters.

Being repaired at Flushing she was towed to England by the Blake, seventy-four, and young Griffin arrived in Chatham, quite tired of the sea, and sick of a seafaring life. At this early period we have to notice the beamings of those high mental qualities which were in after-life developed, in the composition of a poem, giving a full and glowing description of the shipwreck, the perils they had to encounter, and their eventual deliverance.

Having, after some consideration, determined to discontinue a seafaring life, he obtained leave of absence the following year, and shortly after had his name taken off the books of the Admiralty.

He now fixed his choice on the medical profession, but difficulties then stood in the way of his being able to fully accomplish his views, in consequence of unsuccessful speculations in which his father had been involved. Being thrown in a measure on his own resources, his natural energy and engaging address so far favoured him as to succeed in getting himself apprenticed to $\mathrm{Mr}$. Wigram, a respectable general practitioner in Holborn. In this year (1810) he became 
familiar with the composition of medicine, and attended the surgical practice of St. Bartholomew's Hospital under Earle, Harvey, and Abernethy. His zeal and energy soon attracted the notice of this last celebrated surgeon, who, by way of appreciation, gave him, under his hand, an unlimited admission to attend his lectures. His attendance on these lectures, and on St. Bartholomew's Hospital, continued until 1814, when he formed a connexion with a surgeon of East Grimstead as his visiting assistant, with whom he remained for a period of two years.

In 1816 he visited Brussels for the purpose of recruiting his health, which suffered from too close application to study; and in the latter part of that year, in consequence of continued delicacy, he was ubliged to defer the completion of his education, and return to his friends in Ireland, after an absence of eight years. It will be remembered that this was the year in which typhus fever commenced to make such terrible ravages, among the poor especially, in the south of Ireland. The neighbourhood in which he resided soon afforded a wide field for observation, which he eagerly took advantage of, and published his views in the form of a pamphlet, which, at the time, excited some share of attention; and in reference to which he writes in an old pocket-book: " Published a little pamphlet on the epidemic fever then ravaging Ireland. Began to get a little practice without much seeking for it." His name, however, as " a skilful doctor," was spread about, and he established for himself such a reputation, that he was appointed medical attendant to the Currah Dispensary.

In the following year he fixed his residence at Adare, within eight miles of Limerick, and was appointed medical attendant to the Clarina Dispensary. In the latter part of the year 1822 he removed to Rathkeale, opened a small hospital at his own expense for the sick poor, and acquired a tolerable share of practice for the short time he remained there. These various engagements, which the nature of his circumstances made it impossible for him to decline, prevented him from fulfilling his long-cherished desire of completing his medical studies, and obtaining his diploma. His position in this respect subjected him to occasional slights, which were the more annoying to his sensitive mind, as coming from persons far his inferiors, both in education and abilities. There was no remedy, however, but to submit to them until his aim was finally accomplished. In the year 1823, on the death of his friend and relative, Dr. Enright, he was appointed physician to the Pallaskenry Dispensary, in consequence of which he resigned that of Clarina, but was permitted to retain that of Currah as it was in his immediate neighbourhood.

It was here in Pallaskenry that he made an extensive collection of facts and laid the foundation of those views, which he afterwards gave to the medical world in his celebrated work on Spinal Irritation. He now enjoyed an extent of practice equal to what our best country districts afforded, and hoped, as each new year arose, to be able to absent himself from his duties, in order to graduate in one of the 
colleges. An event, however, supervened, which threw this anxious and earnest object of his mind's attention quite out of consideration for the present, and even seemed to have put it beyond his reach for ever. During the last few months of 1823 he began to suffer from a painful affection of his knee and hip, which exhibited in its course and progress all the features of hip disease. He became alarmed, and came to Dublin for advice, where he consulted the late Mr. Colles, who felt a deep interest in his case, and, after several patient examinations gave a decided opinion as to the positive existence of that affection. He recommended him to return home and put in requisition the usual remedies, such as perfect rest, counter-irritation, \&c., \&c.

This sad announcement, coming as it did from an authority upon which he placed so much reliance, had a most depressing effect on his spirits. On his arrival home he appeared quite overcome with anxiety and cares. The mere idea of giving up his practice, at once and entirely, never, perhaps, to resume it again, was more than the strongest mind could bear up against. One circumstance, however, remained, which afforded some consolation, and prevented the blow, heavy as it was, from being altogether so disastrous to him. In the course of his past career be had been able to save out of his income as much as was necessary to complete the medical education of his brother, the present Dr. Daniel Griffin of Limerick, who now lived with him, having already passed through his studies. A short time before, the governors of the dispensary, with feelings of the kindest sympathy for his situation, and the most earnest anxiety to contribute towards his comfort, appointed Daniel as his locum tenens, an arrangement which prevented the institution with which he was connected, together with the practice which he enjoyed, from passing into the hands of strangers.

After a little while his spirits brightened up somewhat, and those traits of natural energy and liveliness of character, which afterwards became so evident, would seem to be manifesting themselves. Severe though the trial was, a state of inaction with him was a perfect impossibility. Having nothing wherewith to employ himself, he turned his attention to light literature. The success and rising fame of his brother Gerald had, in all probability, turned his thoughts in this direction. While on the bed of sickness, and in the height of his sufferings, he took up his pen and commenced writing plays; and it was curious to remark that, as in the case of Cowper, who wrote "John Gilpin" in the midst of the gloomiest apprehensions, most of the productions were of a comic nature. He tried to have one of them introduced on the London stage; it was pronounced by competent judges to be possessed of considerable merit, and far above mediocrity, but merely wanting in that subordinate quality which is understood by the term "stage effect." An idea of his powers in this respect may be conceived by reference to some pieces in prose, of his composition, which were published with collections of tales by his brother Gerald ; one called "The Persecu- 
tion of Jack Edy," in the volume entitled "Hollandtide;" and another under the name of "The Mistake," in the "Tales of a JuryRoom."

The nature of these pieces is not by any means such as would indicate that they had been composed on a sick bed, which, however, was really the fact; and, strange as it may appear, there was hardly a performance of his of any note through life that was not accomplished either in the midst of the most harassing duty or the severest suffering. Fortunately the illness under which he was labouring did not turn out so serious as was anticipated. After a confinement of some months the second hip became affected in the same manner as the first, and both upper extremities participated in the attack. It may be imagined that this event would cast a fresh damper over his spirits, but quite the contrary occurred. The thought immediately flashed across his mind, that the assemblage of symptoms now presenting were but a diffusion of the original attack, and at last clearly revealed its true character. All anxiety and apprehension in regard to organic affection of the hip vanished from his mind, and his views on the nature of his disease were now quite altered. He summoned up un amount of mental energy really astonishing, and lost not a moment in adopting that course of treatment which the features of his case, from its present complexion and the result of past experience, could safely and with success be capable of suggesting. As the first essential and most important step, he removed to the sea side. The effect of the change was no less sudden than surprising. His strength and spirits rapidly rallied, so that in the short space of little more than two months he seemed like one who, from a nerveless and exhausted condition of body, had virtually jumped into a state of perfect health. A state of delicacy which he had long complained of, and which had at times offered serious impediments to his various undertakings through life was, in all probability, of the same nature, and taking its rise from the same cause as the present, though in its combinations, and the several forms it assumed, the idea of an organic disease frequently took possession of his feelings. When he first returned from London in the year 1816 he was seized with pain in the left side, accompanied with cough and slight expectoration. It was feared that phthisis had actually set in, but the symptoms passed off in the course of the year. After this he suffered occasionally from pains in the left side of his head and neck, and upon one occasion got a severe attack of tic doloreux in the eye-brow of the same side. He was accustomed to say he was exactly like two men put together, one of a sound and healthy constitution, and the other always ailing.

During the stages of his weary illness he never lost sight of his profession, feeling a deep and lively interest in its respectability and welfare. He had himself supplied with periodicals, and the best modern works, both on medicine and surgery; a new or important medical fact was as welcome to his ears, and seemed quite as rich a treat to him in his then situation, as in the best days of his untiring 
exertions. In this way he was enabled to fan the lambent flame of research, and to keep pace with the improvements of the day. The idea of perfectly and safely escaping so trying an ordeal seemed to have inspired him with new hope, and convinced him of his great recuperative powers. In fact he felt as if suddenly and altogether endowed with new life and energy; and after taking a review of his position and the prospects before him, he carne to the fixed resolution of attaining his qualification, irrespective of any obstacle that might seem to interfere with such an undertaking; and in fulfilment of this purpose he started for Edinburgh previous to the commencement of the winter session of 1825 .

While there he associated himself with a few fellow-students, who, from mere acquaintances, became warm and united friends. A strong feeling of mutual attachment grew up between them, and they formed an independent group in themselves. They mixed together, studied together, and moved abroad as one body in their daily little walks during the interval of lectures, and those more expanded excursions which were occasionally undertaken by them. The leisure time thus appropriated is not to be conceived as representing hours of idle recreation. It was rather an intellectual pastime in which each gave his contribution or played some part. Griffin, the bright luminary and centre of attraction, as if too careful of himself, or perhaps being sensitive to the northern blast, generally mounted a thick drab outside coat, proof against wind and weather. It was furnished with a pair of immense pockets, all but ready to burst with voluminous notes of lectures, and other curiosities of literature. Upon one occasion, as he appeared slow in coming forth, he was rather abruptly interrogated how it came to pass that he, who had so much wisdom and knowledge within his head, could be able to carry such a weight of learned lumber about him. Without a single word in reply he unloaded himself of the Dublin Weekly Register, and read aloud one of Sheil's brilliant speeches. It was a question which he admired most, - the eloquence of the orator, or the glowing aspiration for freedom he so vehemently proclaimed; but a manly and open declaration soon set the matter at rest, by his professing his unqualified adoption of the maxim,

" Fro rege sæpe, pro patria semper."

On the subject of phrenology he was interesting without being original. He believed that there was more than "something" in its ductrines; but found fault with the nomenclature and the bumpal subdivisions. He also believed that the objections against it, in regard to its tending towards materialism, were not of much importance, for (he observed) "granting that the intellectual faculties, or thinking principles, did solely depend on the special organization of the brain, still the impress of the hand divine must ever be acknowledged; and further, the mere endowing of matter with such wonderful attributes, would be a no less display of infinite wisdom. He was in the habit of exhibiting a peculiar taste for metaphisical disquisi- 
tions, and spoke in admiration of Locke, though he considered the works of Reid and Dugald Stewart as improvenents, particularly in reference to the conceptions of matter, which Locke represented in too unreal a form.

He had a passion for poetry, was an ardent admirer of Moore, and repeated the national melodies with soul-stirring emotion, at times indulging in a vein of sentimental effusion of rather a gloomy and languishing character. He also showed himself familiar with the writings of the most eminent of the British poets. But these allusions may be alien to our present purpose; so we shall advance in the usual footpaths.

In his attendance upon lectures he was regular and constant, though he conceived that in some degree they were a loss of time to him. He had always his note-book at hand, not in order to take down the words of the lecturer, but rather to select those leading facts and important truths which form the basis of skilful practice.

In hospital attendance he was most assiduous. Any case in the least interesting immediately caught his eye, and when it formed the subject of a clinical lecture he was fully informed of all its bearings. And if it should appear to him that any doubt or diffculty had not been sufficiently explained away, he did not fail to express his views or objections, whichever they were, to the lecturer. The late Professor Graham entertained a very high opinion of his capabilities, and paid in open class a very flattering compliment to his exquisite tact in diagnosis. The instance is worth recording. A woman was brought into the Royal Infirmary, with apparent symptoms of acute peritonitis, and was ordered by Dr. Graham to have leeches applied to the abdomen. Griffin pointed attention to the morbid sensibility of the skin, the inconsistent condition of the pulse, and the expression of caprice in the countenance, as suspicious of a simulating disease. Graham smilingly replied by assuring him that it was "all very fine in books, but when coming to practice matters will seem differently." A second bleeding was ordered, but before it was put in practice the patient was seized with a fit of hysteria, which at once revealed the true nature of the attack, and testified most triumphantly to the skill and abilities of the student.

The winter having passed and the lectures reaching their close, the day of trial became nigh at hand, that day whereon the twilight beamings of hope and fear doubtfully agitate the student's mind. Griffin was the first candidate to break the ice, and, as a matter of course, had no difficulty in surmounting the "primum periculum," for the medical degree. Almost contemporaneously he presented himself at the College of Surgeons, and obtained his diploma. All the heavy task being now essentially overcome, and an interval of three months having to elapse before the solemn ceremony of exhibiting in the cap of Hippocrates, brief as the period was, his native genius and enterprising spirit would allow of no rest, and, to the surprise of many, he is shortly after announced in the Edinburgh Medical and Surgical Journal as the author of an VOL. VI. NO. I2, N. S. 
"Essay on the Nature of Pain," a most ingenious production, ably written, and abounding with interesting anecdotes, the basis of which had formed the subject of his inaugural dissertation.

When on the eve of leaving Edinburgh he entertained the notion of fixing his residence in London, as opening a boundless range for his varied and active acquirements. It even at one time amounted to a fixed resolution, in which he was strengthened by the advice and generous counsels of Drs. Graham and Duncan, who could dis. tinguish in him the materials for " a physician in a great city." $\mathrm{He}$ subsequently abandoned this project, and returned to his native soil, the sphere of his usefulness and good deeds, thrice welcome, with honours on his head, and a prospect before him bright and promising from former remembrances. Limerick was now his chief aim, as it had been his early resting-place. It would not be prudent to prematurely leave the village of Pallaskenry, but, as a prelininary, he fitted up a house in a central part of the city as an infirmary for diseases of the eye, and those incidental to women and children. The poor, whom he attended gratuitously, flocked to him in great numbers, and the institution was soon identified with his fame, and was the means of giving him a step in the ladder of promotion.

In 1830 he finally settled in Limerick, having in this year married the niece of Sir Vere Hunt, Bart., a very early acquaintance whom he had met in his boyhood days, while residing at Sir Vere's house in London, previous to his going to sea. As the fruit of that marriage he has left one son, fifteen years of age, who has already given signs of much promise. From this period his rise was steady and progressive; his income, rapidly increasing after the first few years, soon reached that amount which entitled him to the rank of a head physician.

The lamented death of the distinguished novelist, in 1840, was a source of long and enduring sorrow to his over sensitive feelings. As an instance of the love and devoted attachment which reigned in this united family, we here annex, from the Life of Gerald, published by the present Dr. Daniel Griffin of Limerick, a portion of the Dedication, to the subject of the present memoir: "whose affectionate care," he says, "fostered that talent in his youngest brother, from which the public has derived such solid pleasure," and " in memory of the deep and unchanging affection that brother always bore him."

As a practitioner Dr. Griffin was unbounded in his resources, yet withal extremely cautious, and trusted much to the powers of nature. He was sanguine to a degree, never despairing while a shadow of hope remained. He felt an intense interest in his patients, and in his anxiety to have the necessary measures faithfully carried out, he became at once the nursetender and the physician. He was connected with several of the medical institutions of his native city, and contributed largely towards their improvement and efficiency; he delivered some very interesting lectures in the board-room of the county infirmary, which were well attended by amateurs and pupils; 
he also endeavoured to establish a school of medicine and surgery, but failed in the attempt, for want of active co-operation on the part of others.

In medical politics he was a reformer; and in his evidence before the Committee of the House of Commons on the Medical Charities he offered many able and valuable suggestions for their better regulation. He was a member of the Corporation of Limerick, and had within reach the highest honours that body could confer. When the question of nationality was debated he was at his post, and manfully avowed his sentiments; but he never obtruded his opinions in private, neither was he dissuaded from avowing them, when necessary, from a feeling of sickly timidity. He felt for the wrongs of his country, and sighed for her regeneration.

He was a patron of the fine arts and general literature; and he stood deservedly high in the good opinion of his profession. In the relations of social life he was bland and amiable; and he had the singularly good fortune of attaching to himself a large circle of acquaintances; his private worth and genuine philanthropy were alike proverbial; he was the esteemed of many and the favourite of all; in unpretending charity he was profuse, and in self-denying virtue unequalled; as a friend he was sincere and upright; as a man of feeling he was kind and really generous; and as a Christian he was religious without ostentation. No man could review the past with a more sterling sense of conscious rectitude, and no man could look to the future with brighter hopes of eternal reward.

In him were centred those rare intellectual excellencies which constitute the all-important attributes of a "medical mind." To the faculty of comparing and generalizing facts in the spirit of true philosophy, he had superadded the habits of close and faithful observation. The several original contributions he has made to the medical literature of his country deservedly give him place among its eminent medical men.

His brilliant career was cut short in consequence of his enthusiastic devotion to the best interests of the profession. As the result of untiring mental energy, coupled with great and overpowering bodily labours, his nervous system became quite unhinged, and in the beginning of April last he began to be affected with pain in the left side of the head. As this was no uncommon thing with him, he treated it as rheumatism, with leeches, blisters, colchicum, turpentine, \&c., all the while going about and attending to business. He usually got relief on the application of remedies, and then after a week or so fell back again. After four or five weeks he consented, under the persuasion of his friends, to give up business and go to the country. He now noticed a difficulty in recollecting particular words, which embarrassed his mind in speaking or writing to patients; and his letters, though otherwise correct and to the purpose, contained several erasures or, at times, the substitution of one word for another. He used to say: "It is a most curious thing: I kurow as well as possible what I am 
going to say, but, if I were shot for it, I cannot think of the particular word." The worst sign about him was complete absence of any sense of danger. It was now obvious that he laboured under a chronic inflammation of the brain, which, notwithstanding every possible effort that could be devised, pursued the usual melancholy course; paralysis of the right side quickly supervened, complicated with a total interruption of conversational powers; a general debility and complete languor ensued; and he continued in the same distressing and hopeless state till the termination of his earthly sufferings, which took place on the 9 th of July of the present year.

We regret that the length to which this memoir has extended prevents us from alluding in a particular manner to Dr. Griffin's able writings. The following is a list of his professional publications, and the papers published by him in the different medical periodicals:

1. A Treatise on Fever. 8vo. pamphlet. 1818.

2. An Essay on the Nature of Pain, with some Considerations on its principal Varieties as connected with Disease, and Remarks on the 'Treatment: being the Subject of an Inaugural Dissertation delivered at the University of Edinburgh. 8vo. pp. 86. Edinburgh, Moir. 1826.

3. Observations on Functional Affections of the Spinal Cord and Ganglionic System of Nerves, in which their Identity with Sympathetic, Nervous, and Imitative Diseases is Illustrated. By William Griffin, M.D., \&c., and Daniel Griffin, M. D. London, Burgess and Hill. 1834. 8vo. pp. 247.

4. Observations on the Cholera, as it appeared in Limerick in 1831-2. 1834.

5. Medical and Physiological Problems, being chiefly Researches for correct Principles of 'Treatment in disputed Points of Medical Practice. By William Griffn, M. D., and Daniel Griffin, M. D. London, Sherwood and Co. 1843. 8vo. pp. 356.

Dr. Griffin wrote some papers in the Medical and Physical Journal, and was a constant contributor to the Dublin Medical Journal, both in its original and in its present form. The Medical and Physiological Problems, which he afterwards published in connexion with his brother, first appeared, together with other papers, in detached essays scattered over seven volumes of our former series; and the last of his labours (a paper on abortion) appeared in the Number for May, 1847. We understand he was preparing a work on cholera at the time of his death, which is now nearly ready for publication. 


\section{EPITAPH UPON BOYLE GODFREY, ALCHYMIST, \&c.}

Is the Number for May, 1846, we gave an eulogium extracted from the Minute Book of the Dublin Medico-Philosophical Society, upon Isaac Butler, the celebrated Dublin astrologer, caster of nativities, and almanac maker, - the pupil of Dr. John Whaley, and withal beadle to the Worshipful Company of the Apothecaries,--who died in 1755. In the same curious old manuscript work we find the following epitaph upon the celebrated alchymist, Boyle Godfrey. It was written by the learned and facetious Dr. Charles Smith, author of the Histories of the Counties of Cork and Waterford. It was read at a meeting of the Society upon the lst of July, 1756, and is inserted in the Minutes of the 15 th of that month $(a)$.

\section{EPITAPHIUM CHEMICUM.}

Here lieth to digest, macerate, and amalgamate with clay,

In Balneo Arena,

Stratum super stratum,

The Residuum, Terra Damnata, and Caput Mortuum, Of BOYLE GODFREY, CHIMIST, And M. D.

A man who in this earthly Laboratory

Pursued various processes to obtain Arcanum Vitce,

Or the Secret to Live:

Also Aurum Vita,

Or the Art of getting, rather than making, Gold. Alchemist like,

All his labour and propition, As Mercury in the fire, evaporated in fumo.

When he dissolved to his first principles, He departed as poor

As the last drops of an alembic :

For riches are not poured

On the Adepts of this world. Thus,

Not Solar in his purse,

Neither Lunar in his disposition,

Nor Jovial in his temperament;

Being of Saturnine habit,

Venereal conflicts had left him,

And Martial ones he disliked.

With nothing saline in his composition

All Salts but two were his Nostrums.

The Attic he did not know

And that of the Earth he thought not Essential;

But, perhaps, his had lost its Savour.

(a) Boyle Godfrey published " A New Method of Extinguishing Fires," London, 1727, 8vo.; and a sort of receipt-book entitled, "Miscellaneous Ex. periments and Observations on various Subjects," London, 1737, 8vo. Of this latter there was a Dublin reprint. 
Though fond of news, he carefully avoided

The fermentation, effervescence,

And decupilation of this life.

Full seventy years his exalted essence

Was hermetically sealed in its terrene matrass ;

But the radical moisture being exhausted, The Elixir Vita spent,

Inspissated and exsiccated to a cuticle,

He could not suspend longer in his vehicle,

But precipitated gradatim Per companam,

To his original dust.

May that light, brighter than Bolognian Phosphorus,

Preserve him from the Incineration and Concremation

Of the Athanor, Empyreuma, and Reverberatory

Furnace of the other world,

Depurate him, like Tartarus Regeneratus,

From the Foces and Scoria of this;

Highly rectify and volatilize

His Etherial Spirit,

Bring it over the helm of the Retort of this Globe,

Place in a proper Recipient,

Or Crystalline Orb,

Among the elect of the Flowers of Benjamin,

Never to be saturated

Till the general Resuscitation,

Deflagration, and Calcination of all things,

When all the reguline parts

Of his comminuted substance

Shall be again concentrated, Revivified, alcholized,

And imbibe its pristine Archeses;

Undergo a new transmutation, Eternal fixation,

And combination of its former aura;

Be coated over and decorated in robes more fair

Than the magistie of Bismuth,

More sparkling than Cinnabar, Or Aurum Mosaicum.

And being found Proof Spirit,

Then to be exalted and sublimed together

Into the Concave Dome

of the highest Aludel in Paradise.

\section{SILVESTER O'HALLORAN.}

IN our memoir of this distinguished surgeon we omitted to mention in the bibliography, the following tract:

"A concise and impartial Account of the Advantages arising to the Public from the general Use of a new Method of Amputation." Dublin, S. Powell. 1763. 8vo. pp. 15. It was dedicated to Ezekiel Nesbit and the College of Physicians, and to John Nichols and the College of Surgeons. 